\title{
AS NOVE EDIÇÕES DO COLÓQUIO DE CARTOGRAFIA PARA CRIANÇAS E ESCOLARES E SUAS AGONISTICAS ${ }^{1}$
}

\author{
Valéria Cazetta ${ }^{2}$
}

Resumo: Quatro autores não geógrafos: Adélia Prado, Jorge Luís Borges, Walter Benjamin e Georges Didi-Huberman; dois diálogos, um com um estudante universitário de geografia e outro com uma professora-geógrafa universitária; e as nove edições do Colóquio de Cartografia para Crianças e Escolares. Eis nosso quebra-cabeça, pois. Nosso intento foi apresentar um plano de composição das agonísticas do campo da cartografia escolar brasileira em suas distintas ambiências, procurando destacar as direções do pensamento dos professores formadores de professores e os ecos desse pensamento na formação de professores de geografia da educação básica. Por meio de dois estudos, concluímos o texto advogando em prol de uma educação geográfica e cartográfica ancorada no procedimento arquivístico.

Palavras-chave: cartografia escolar, educação geográfica, ensino de geografia, educação.

\section{OF THE NINE EDITIONS OF THE CARTOGRAPHY COLLEGE FOR CHILDREN AND SCHOOLS AND THEIR AGONISTICS}

\begin{abstract}
Four non-geographers: Adélia Prado, Jorge Luís Borges, Walter Benjamin and Georges Didi-Huberman; two dialogues, one with an university student of geography and another one with an university geographer-professor; and the nine editions of the Colloquium of Cartography for Schoolchildren. Here are our puzzle, therefore. Our intention was to present a composition plan of the agonists of the field of brazilian school cartography, in its different ambiences, trying to highlight the directions of the teachers thinkings whom graduate other teachers and the echoes of that thought in the formation of geography teachers of basic education. Through those two studies we conclude the text, advocating for a geographic and cartographic education anchored in the archival procedure.
\end{abstract}

Keywords: school cartography, geographic education, geography teaching, education.

\footnotetext{
${ }^{1}$ Texto tributário de nossa participação na mesa-redonda "O estado da arte da cartografia escolar: múltiplas perspectivas", no dia 16/08/2017, como parte da programação do I Encontro Livia de Oliveira: Cartografia Escolar e Ensino de Geografia, realizado no Instituto de Geociências e Ciências Exatas (IGCE), da Universidade Estadual Paulista (Unesp), em Rio Claro (SP), nos dias 15 e 16 de agosto de 2017.

${ }^{2}$ Docente da Escola de Artes e Ciências Humanas (EACH) da Universidade de São Paulo (USP). Endereço para contato: Rua Arlindo Bettio, 1000, Vila Guaraciaba, São Paulo/SP (CEP.: 03828-000); e e-mail: vcazetta@usp.br
} 


\section{INTRODUÇÃO}

A conversação inicia-se, neste ensaio, com quatro autores: Adélia Prado, Jorge Luís Borges, Walter Benjamin e Georges Didi-Huberman cujos escritos vinculam-se ao tema da cartografia e da geografia, mais por meio do gesto de compor modos de existência - que oscilam entre as coisas chãs ${ }^{3}$ e as imaginações espaciais - com o pensamento cartográfico e geográfico, e menos com a meta de estabelecer algum procedimento exclusivo e eficaz acerca dos saberes geográficos e cartográficos em sua interface com o campo educacional. Nosso intento, com isso, foi buscar uma apropriação dos referidos autores, permitindo-nos dessacralizar um uso, grosso modo, sagrado dos produtos cartográficos que é feito por nós, geógrafos, professores, professores-pesquisadores e estudantes, vinculados ao campo da ciência geográfica e cartográfica. $\mathrm{E}$, por meio de dois diálogos, com um estudante da graduação em geografia e uma professora universitária, respectivamente, e das nove edições do Colóquio de Cartografia para Crianças e Escolares, apresentamos nossa hipótese de trabalho: a disputa acerca de uma versão única do que deve ser a cartografia e seus produtos, tanto no escopo da educação geográfica como no campo da pesquisa acadêmica vinculada à temática da cartografia escolar. Para dirimir incompreensões tragadas por ressentimentos, seja lá de que ordem for, advogaremos em prol de uma educação geográfica e cartográfica ancorada no procedimento arquivístico, por meio do qual conexões podem ser estabelecidas entre as diversas linguagens criadas por nós na lida ordinária no presente de outrora.

\section{ALGUNS ESCRITOS QUIMÉRICOS}

Escritos quiméricos acerca dos mapas e da cartografia, e da geografia; não são verdadeiros nem falsos; importantes ou desimportantes. Nada querem provar ou refutar. Pairam na poeira do tempo e nos espaços intervalares que, outrora, ocuparam uma vida e outra, e outra, e outra e...

Adélia Prado (2006, p.47), poetisa, professora, filósofa e contista brasileira, assevera que os mapas a

[...] descansam, mais em seus desertos que em seus mares, onde não mergulha porque mesmo nos mapas são profundos, voraginosos, indomesticáveis.

Como pode o homem conceber o mapa?

Aqui rios, aqui montanhas, cordilheiras, golfos, aqui florestas, tão assustadoras quanto os mares.

As legendas dos mapas são tão belas que dispensam as viagens.

Você está louca, dizem-me, um mapa é um mapa.

Não estou, respondo.

O mapa é a certeza de que existe O LUGAR, o mapa guarda sangue e tesouros $[\ldots]$

Os mapas são necessariamente interpelativos e lê-los requer aceitar o jogo paradoxal entre o tempo (passado, presente e futuro) e o espaço ali apresentado por

\footnotetext{
${ }^{3}$ DIDI-HUBERMAM, 2017, p. 28.
} 
meio de suas superfícies lisas, sem rugosidades e, aparentemente, sem agonísticas. Ao tocarmos um mapa com nossas próprias mãos e olhos, as fronteiras tornam-se fáceis de serem atravessadas, os rios e mares passam a ser transponíveis a nado, os mistérios das florestas ficam impassíveis, distâncias longas e espaços amplos comprimem-se, os problemas socioambientais desaparecem ou ganham legendas com cores blasé. O mapa evidencia a certeza de que o existe o lugar, mas o mapa também guarda sangue e tesouros, com seus ecos discursivos disparados pelas corporeidades, atravessando o espaço pela flecha do tempo.

Jorge Luis Borges (1982, p. 117), poeta, tradutor, crítico literário e ensaísta, aborda de forma bem humorada a busca da totalidade e fidedignidade na representação do espaço pela cartografia, na escala 1 por 1 , de modo que o mapa possa coincidir com o espaço, a ponto de confundir o que seja um e outro.

Naquele império, a arte da cartografia alcançou tal perfeição que o mapa de uma única província ocupava toda uma cidade, e o mapa do império, toda uma província. Com o tempo, esses mapas desmesurados não foram satisfatórios e os colégios de cartógrafos levantaram um mapa do império, que tinha o tamanho do império e coincidia pontualmente com ele. Menos afeitas ao estudo da cartografia, as gerações seguintes entenderam que esse dilatado mapa era inútil e não sem impiedade o entregaram às inclemências do sol e dos invernos. Nos desertos do oeste perduram despedaçadas ruínas do mapa, habitadas por animais e por mendigos; em todo o país não há outra relíquia das disciplinas geográficas. (Extraído de Viajes de Varones Prudentes, de Suaréz Miranda, livro quarto, cap. XIV, Lérida, 1658. Citado por Jorge Luis Borges, História Universal da Infâmia "Etc.") ${ }^{4}$.

Entregues também às inclemências do sol e dos invernos e dos verões foram os guias cartográficos urbanos em papel, constituídos por inúmeros mapas em escalas tanto detalhadas (de ruas e avenidas) quanto generalizadas (das principais rodovias dos estados brasileiros). Consultar esses mapas costumava ser um exercício geográfico por excelência: pensar em várias escalas nas suas relações parte e todo. Até pouco tempo, esses guias ainda circulavam pelas livrarias ou bancas de jornais, dizendo-nos de um modo de pensar, imaginar e deslocar-se no espaço, próximo ou distante; e os taxistas eram seus principais usuários, afinal, nas grandes capitais brasileiras era difícil ter o mapa da cidade inteira na "cachola" ou desdobrado sobre as palmas das mãos.

No livro Quando as imagens tomam posição, o filósofo, historiador, crítico de arte e professor da École des Hautes Études en Sciences Sociales, Georges DidiHuberman (2017, p. 15) afirma que "para saber é preciso tomar posição". Nesse excerto há matéria geográfica e cartográfica adensada; tomar posição implica situarse/localizar-se sobre um dado pedaço de chão - com suas respectivas linhas de latitude e de longitude -, atravessado por inúmeras trajetórias humanas e inumanas. Essas reverberam em nossa corporeidade mesmo que, de pronto, não percebamos seus efeitos, os quais operam como ecos; estes partem de vários lugares, incluindo o próprio corpo cuja pele é uma dobra do espaço - desse chão que pisamos. Tomar posição não se trata de um gesto simples, pois envolve duas ações: 1) encarar o que está fora do nosso alcance, "mas que, em grande parte, condiciona nosso

\footnotetext{
${ }^{4}$ Apud ECO, Umberto. O segundo diário mínimo. Rio de Janeiro: Record, 1993, p. 213.
} 
próprio movimento, logo, nossa posição" (DIDI-HUBERMAN, 2017, p.15); e 2) desejar, exigir algo, no sentido de nos localizarmos no tempo presente ancorados no futuro, isto é, em uma dada ideia de futuro. Essas duas ações sobrepostas, elencadas por Didi-Huberman (encarar o não-saber a partir do presente e de uma dada ideia de futuro), dizem respeito a um espaço e tempo da vida que exige de nós pensar sincronicamente em movimentos multiescalares.

No conto "Porcelanas da China", de Walter Benjamin (2000, p.15) - ensaísta, crítico literário, tradutor, filósofo e sociólogo judeu alemão -, lê-se:

A força de uma estrada do campo é diferente quando caminhamos por ela e quando voamos sobre ela num avião. Da mesma forma, a força de um texto quando lido é diferente de sua força quando copiado. Quem voa vê apenas o modo como a estrada penetra pela paisagem, como ela se desdobra de acordo com as leis da paisagem ao seu redor. Somente quem anda a pé pela estrada conhece a força que ela tem, e como, da mesma paisagem que para quem voa é apenas uma planície aberta, ela desvenda distâncias, mirantes, clareiras, panoramas a cada curva como um comandante posicionando soldados numa frente de batalha. É somente o texto copiado que comanda, assim, a alma de quem se ocupa dele, ao passo que o mero leitor jamais chega a descobrir os novos aspectos de seu interior que são abertos pelo texto, a estrada corta ao meio a floresta que vai constantemente se fechando atrás dela: porque o leitor segue o movimento de sua mente no voo livre da imaginação, enquanto quem copia submete a mente ao seu comando.

No trecho supracitado também há elementos geográficos acerca dos efeitos de gestos como caminhar e sobrevoar uma estrada de terra: as relações de proximidade e de distanciamento com as coisas do mundo; a primeira proporcionada pela caminhada e a segunda pelo sobrevoo. Daí que "para saber é preciso, pois, manter-se em dois espaços e em duas temporalidades ao mesmo tempo" (DIDIHUBERMAN, 2017, p.16): aproximação e distanciamento; "aproximação com reserva, afastamento com desejo" (DIDI-HUBERMAN, 2017, p. 16). Uma composição de movimentos, forças e diferentes escalas intercambiando-se.

O espaço sobre o qual nos deslocamos diariamente, a pé, de automóvel, de avião etc., é forjado por vários tipos de trajetórias (humanas e não-humanas) e linguagens; essas fabricadas por nós, na tentativa de dar a ver e fazer falar esse espaço que se dobra em nosso corpo por meio da pele - superfície clivada pela passagem inexorável do tempo. Nesse sentido, Adélia Prado, Jorge Luís Borges, Georges Didi-Huberman e Walter Benjamin, nos apresentam pistas acerca das conexões entre espaço-tempo, corpo e linguagem, que exploraremos partindo de duas notas decorrentes de diálogos mantidos com um estudante de graduação em Geografia e uma amiga, professora-pesquisadora na área de Geografia Regional, ambos de universidades públicas.

Portanto, a conexão entre as duas notas mencionadas e as nove edições do Colóquio de Cartografia para Crianças e Escolares seria de ecos e, ao mesmo tempo, da própria abertura desses ecos às suas reverberações em nós e nas coisas do mundo. Isto é, os diálogos travados por nós, professores e estudantes, tanto no exercício da docência (concernente à formação de professores de geografia) como da pesquisa (no campo da educação geográfica e dos estudos culturais, em nosso 
caso), ambos estariam sob uma captura discursiva produzida por nós mesmos, porém pouco problematizada.

\section{NOTA 1: O ESTUDANTE E OS MAPAS}

Recentemente, um jovem estudante procurou-nos para apresentar o trabalho final elaborado para uma das disciplinas de Cartografia da graduação (bacharelado e licenciatura) em Geografia, direcionada à elaboração de mapas temáticos. Por meio de três softwares, dois voltados para a cartografia temática, Philcarto e Cartes and Donnes, e outro para a edição vetorial, Adobe Illustrator, um conjunto de mapas sobre a agropecuária do estado e do município de São Paulo fora elaborado a partir do levantamento de dados em sítios governamentais como: Instituto Brasileiro de Geografia e Estatística (IBGE); Produção Pecuária Municipal (PPM); Produção Agrícola Municipal (PAM - ano de 2016); além de dados do Censo Agropecuário (ano de 2006) e da Defesa Agropecuária. O autor primou tanto pela qualidade estética quanto pelos elementos cartográficos - título, escala, fonte dos dados, legenda, projeção, e norte geográfico - indispensáveis aos mapas, ao menos aqueles oficiais, produzidos em âmbito acadêmico e institucional.

Ao deslocarmos o olhar sobre os mapas elaborados, distribuídos em páginas e mais páginas, no ecrã do computador, inúmeras hipóteses eram suscitadas por nós a ele; um misto de frustração e espanto evidenciava-se em seu olhar - gesto, supostamente improvável para um trabalho tão bem cuidado em sua elaboração, cremos, pensara o estudante. Não falamos com ele sobre gestos e olhares; detivemo-nos somente à conversação sobre aquelas superfícies lisas e horizontais apresentadas com certo entusiasmo inicial; de fato, estavam bonitas e com matizes de cores bastante interessantes, mas à qualidade estética e instrumental desses dispositivos é preciso aliar o pensamento, do contrário ter-se-ão trabalhos e investimentos (pessoal, temporal e espacial) tragados pela pressa pragmática e desatenta do contemporâneo, produzida, diga-se de passagem, por nós.

Como não rememorar as disciplinas de Cartografia e Sensoriamento Remoto cursadas por nós na graduação em Licenciatura em Geografia, em meados da década de 1990? Ou de nosso professor de geografia, ainda na educação básica, quando dizia: "A matéria de Geografia se estuda com o corpo; ao tocarmos os mapas com nossas mãos e nossos olhos, as geografias se desdobrarão em nossa imaginação. Vocês perceberão a importância da representação, bem como seus limites e paradoxos". Ecos de outrora e reminiscências que se cruzam, agora, com as certezas cartográficas de um jovem estudante de geografia. Continuaria o espaço a ser concebido como sinônimo de espacialização e distribuição de fenômenos, agora menos em papel e mais sobre as telas de smartphones, computadores, notebooks? Sim, continuaria, e decorreria de uma cultura cartográfica em geografia, forjada por "um conjunto aparentemente estável e autojustificado de conteúdos, cujo ensino é mais prescritivo que reflexivo" (GIRARDI, 2014, p. 863); essa cultura cartográfica em geografia seguiria desdobrando-se na Educação Básica.

\section{NOTA 2: A PROFESSORA DE GEOGRAFIA REGIONAL E OS MAPAS}


Nossa relação com os lugares, os locais e o mundo é, necessariamente, geográfica e política; em qualquer diálogo, por mais simples que seja, sempre nos é requerido espécie de um arquivo mental, que também poderíamos chamar de arquivo enciclopédico, no sentido de acervo. Empregamos de modo proposital o adjetivo enciclopédico à ideia de arquivo/acervo, pois o uso das enciclopédias, outrora analógicas, incluindo aí os Atlas (gerais e escolares), foi substituído pelas enciclopédias digitais, tornadas, com pouca variação, uma de nossas referências de mundo; vide a quantidade de acessos diários realizados por nós junto à Wikipédia: $A$ enciclopédia livre.

Os estudos voltados para a Cartografia Escolar têm advertido, desde a realização do I Colóquio de Cartografia para Crianças e Escolares sobre a imprudência de se pintar/colorir/memorizar mapas, bem como de qualquer atividade relacionada a práticas de tipo mnemônica como: decorar o nome de capitais (e seus respectivos estados), dos principais rios e seus afluentes, as fronteiras "naturais" entre um estado e outro, os nomes e os formatos dos continentes. Ao contrário, tais estudos apregoam a importância de se aprender sobre o processo de elaboração de um mapa em sua relação com a corporeidade e o espaço; processo esse eivado, na prática, de inúmeras simplificações. Não estamos a dizer que tal processo seja desimportante, no entanto, as reverberações disso junto à prática docente reduziu a iniciação cartográfica em contexto escolar, ao ensino e aprendizado dos pontos de vista vertical e oblíquo, os elementos que um mapa deve conter, os pontos cardeais etc. Eis aqui o ponto de inflexão.

Em uma das conversas com nossa amiga-professora acerca das implicações do trabalho do professor-pesquisador na universidade, concluímos que algumas práticas rechaçadas pelos estudiosos da Cartografia Escolar faziam-nos falta ao abordarmos conteúdos concernentes à Geografia Regional brasileira: ter na memória o mapa do Brasil e seus respectivos estados, o da América do Sul, o da América Latina... Disse-nos essa amiga: "Percebi que os estudantes não sabiam a localização aproximada dos estados do Brasil no mapa, ao mencionar como ocorreu o processo de formação das regiões brasileiras e suas tipologias. Daí, não hesitei e fiz uma atividade com mapas contendo somente a divisão dos estados. Eles deveriam preenchê-los. Constrangidos ao me entregarem a atividade, muitos estudantes disseram que precisariam atentar-se a esses conhecimentos, pois, de fato, seria um contrassenso estudar geografia regional sem ter um mapa mental do Brasil, entre outros". Heresias à parte: memorizar mapas e cartografias do mundo afetaria de modo doentio nosso pensamento espacial? Se assim for, tornemo-nos, então, cada mais vez mais doentes e adictos de mapas e das geografias mundanas a invadirem os ecrãs de nossos dispositivos tecnológicos.

Dizeres de poetas, ensaístas, filósofos, professores, estudantes; daqueles/as que se atribuíram a tarefa de pensar a partir de uma linguagem situada na fronteira indiscernível entre exatidão cartesiana, as imaginações e as narrativas espaciais, e as corporeidades. Hesitações acerca dessas superfícies lisas: mapas profanados a partir de suas impossibilidades nos diversos suportes - papel, pele, ecrã das telas de smartphones/computadores. Impossibilidades de qualquer ordem de correspondência entre os mapas e as coisas chãs, mas que podem ser conectadas desde uma composição amalgamada pela vida em suas impermanências micropolíticas ${ }^{5}$.

\footnotetext{
${ }^{5}$ Na acepção de DELEUZE e GUATT ARI, 2012.
}

Estudos Geográficos, Rio Claro, 16(1): 159-179, jan./jun. 2018 (ISSN 1678-698X) 


\section{CONEXÕES ENTRE O ESTUDANTE E A PROFESSORA: DOS GESTOS CARTOGRÁFICOS NA COMPOSIÇÃO DE GEOGRAFIAS}

Aliada às problemáticas apresentadas por nós via notas/diálogos têm-se outras duas. A primeira enunciada desde o final da década de 1970 quando da realização, no Brasil, dos primeiros estudos ${ }^{6}$ sobre o uso da linguagem cartográfica em contexto escolar: os professores de geografia da Educação Básica seguem com conhecimentos exíguos acerca das possibilidades do uso dos saberes cartográficos em âmbito escolar. A segunda diz respeito à linguagem cartográfica que, integrada às Tecnologias da Comunicação e da Informação (TIC), espraia-se cada vez mais no tecido social, ao menos no Ocidente, demandando novos estudos, seja acerca de como os professores de geografia da Educação Básica têm forjado práticas educativas com a linguagem cartográfica sob esse novo suporte, seja como os professores dos cursos de licenciatura em Geografia, isto é, formadores de professores, têm pensado as disciplinas da Cartografia em suas dobras pedagógicas.

Três ponderações fazem-se necessárias.

1) Não se trata aqui de advogar em prol do uso instrumental dos dispositivos cartográficos, mas de empregá-los como linguagens de uma escrita outra da vida: produção de pensamento e conhecimento em ato na composição do grande arquivo do mundo. As apostas de certos estudos têm seguido nessa direção, no sentido de ampliar e não de reduzir e simplificar produções humanas como mapas, croquis, cartas topográficas, aparelhos de Global Position Systems, bússolas, entre outras linguagens. Possivelmente alguns pesquisadores-professores possuem ideias equivocadas acerca das dobras educativas da maquinaria geográfica e cartográfica nos âmbitos tanto da formação de professores quanto da vida cotidiana. Não basta o professor de geografia da Educação Básica saber como se empregam os materiais supracitados se esse conhecimento não for conectado a uma rede de outros saberes, contextos culturais e arquivos. A mobilização desse conjunto de variáveis dependerá do quanto aquilo que aprendemos nos catapultará para escavar as camadas mais profundas do arquivo do mundo - abrigadas sob as camadas depositadas pelo tempo - como o fizeram a arqueóloga franco-brasileira Niède Guidon, no Parque Nacional da Serra da Capivara (PI), e Michel Foucault nos estudos que levou a cabo por meio de seus gestos arqueogenealógicos. Aqui não empregamos a noção de arqueologia como metáfora, mas como modo de vida lastreado por escavações.

2) Nos cursos de licenciatura em geografia há ainda certo consenso entre a maioria dos docentes, seja entre aqueles responsáveis pelas disciplinas de cunho técnico-científico (como Geomorfologia, Cartografia, Sensoriamento Remoto, Climatologia etc.), seja entre os/as responsáveis pelas disciplinas educacionais, de que para ser professor/a bastaria simplificar o ensino dos conteúdos tidos como mais complexos e difíceis. Entretanto, tais simplificações funcionam como uma

\footnotetext{
${ }^{6}$ No livro organizado por Almeida (2010), intitulado Cartografia Escolar, é possível encontrar os/as autores/as brasileiros/as que realizaram as primeiras pesquisas das quais se tem conhecimento, datadas do final da década de 1970 em diante, acerca da linguagem do mapa e seus desdobramentos em âmbito escolar.
} 
espécie de sonegação às crianças e adolescentes do direito pétreo ao arquivo do mundo. Uma aula sobre os elementos cartográficos de escala, projeção e simbologia pode ser enfadonha, mas pode, ao contrário, fomentar o interesse dos estudantes do significado de pensar em várias escalas, projeções e simbologias - raciocínio geográfico por excelência (BANYAl, 1995, 1998; SANTOS, 2000).

3) Haveria uma espécie de disputa de narrativa no âmbito das nove edições dos colóquios realizados, até o presente momento, acerca do que deve ser/é a cartografia escolar e não do que poderia esse campo - em suas interfaces com as áreas da Educação, Cartografia, Geografia, Astronomia, Sensoriamento Remoto, Sistema de Informação Geográfica (SIG), e plataformas como Google Earth e Google Maps - via uma educação pelo arquivo (AQUINO, 2017).

Nesse texto, debruçar-nos-emos sobre a terceira problemática.

\section{OS COLÓQUIOS E SUAS POLÊMICAS}

Desde a realização do I Colóquio de Cartografia para Crianças, em 1995, na Universidade Estadual Paulista (Unesp), Rio Claro/SP, passaram-se 22 anos. Para se ter um panorama das edições já realizadas elaboramos a tabela 1, incluindo a proposta do $X$ Colóquio $^{7}$, com os títulos atribuídos a cada um desses eventos científicos como forma de adensar as discussões em pauta. Nos três primeiros, os títulos eram homônimos ao nome do evento: Colóquio Cartografia para Crianças, e a partir da quarta edição foi ampliado para Cartografia para Escolares, procurando abarcar o conjunto de trabalhos circunscritos não somente no âmbito da cartografia infantil, mas nas ambiências escolares em geral. Poderíamos afirmar que essa foi a primeira polêmica evidenciada nas mesas-redondas dos três primeiros colóquios.

Tabela 1: Edições do Colóquio de Cartografia para Crianças e Escolares: período de 1995 a 2018 .

\begin{tabular}{|c|c|c|c|}
\hline $\begin{array}{c}\text { Colóquio } \\
\text { Ano }\end{array}$ & Local, Instituição & $\begin{array}{l}\text { Tema do Colóquio e } \\
\text { Evento sobreposto }\end{array}$ & $\begin{array}{c}\text { Coordenação } \\
\text { Comissão Organizadora }\end{array}$ \\
\hline $\begin{array}{c}\text { I } \\
1995\end{array}$ & $\begin{array}{l}\text { Rio Claro (SP) } \\
\text { Unesp (IB) }\end{array}$ & CARTOGRAFIA PARA CRIANÇAS & $\begin{array}{l}\text { Prof. }^{\text {as }} \mathrm{Dr}^{\text {as }} \text { Regina Araújo de Almeida } \\
\text { (USP) e Rosângela Doin de Almeida } \\
\text { (UNESP). }\end{array}$ \\
\hline $\begin{array}{c}\text { II } \\
1996\end{array}$ & $\begin{array}{c}\text { Belo Horizonte/MG } \\
\text { UFMG }\end{array}$ & CARTOGRAFIA PARA CRIANÇAS & $\begin{array}{l}\text { Prof. }^{\text {as }} \text { Dr. }^{\text {as }} \text { Janine Gisele Le Sann } \\
\text { (UFMG) e Márcia Maria Duarte dos } \\
\text { Santos (UFMG). }\end{array}$ \\
\hline $\begin{array}{c}\text { III } \\
1999\end{array}$ & $\begin{array}{l}\text { São Paulo/SP } \\
\text { FFLCH/USP }\end{array}$ & CARTOGRAFIA PARA CRIANÇAS & Prof. Dr. Clézio dos Santos (UFRRJ) \\
\hline $\begin{array}{c}\mathrm{N} \\
2001\end{array}$ & $\begin{array}{l}\text { Maringá/PR } \\
\text { UEM }\end{array}$ & $\begin{array}{l}\text { CARTOGRAFIA PARA ESCOLARES } \\
\text { I Fórum Latino Americano de Cartografia para } \\
\text { Crianças }\end{array}$ & Prof. $^{a}$ Dr. $^{a}$ Elza Yasuko Passini (UEM) \\
\hline $\begin{array}{c}V \\
2007\end{array}$ & $\begin{array}{l}\text { Niterói/RJ } \\
\text { UFF }\end{array}$ & $\begin{array}{c}1^{\circ} \text { SIMPÓSIO IBERO-AMERICANO DE } \\
\text { CARTOGRAFIA PARA CRIANÇA: } \\
\text { Pesquisa e perspectiva em Cartografia para } \\
\text { Escolares } \\
\text { V COLÓQUIO CARTOGRAFIA PARA } \\
\text { CRIANÇAS E ESCOLARES } \\
9^{\circ} \text { ENPEG - Encontro Nacional de Prática de } \\
\text { Ensino de Geografia }\end{array}$ & $\begin{array}{l}\text { Prof. Dr. Jader Janer M. Lopes (UFJF) } \\
\text { e Prof. }{ }^{\text {a }} \text { Dr. }{ }^{a} \text { Tomoko I. Paganelli } \\
\text { (UFRJ) }\end{array}$ \\
\hline
\end{tabular}

\footnotetext{
${ }^{7}$ Será realizado no período de 9 a 12/07/2018, na Faculdade de Educação (FE) da Universidade de São Paulo (USP). Para mais informações acessar http://veradata.com.br/cartografiaescolar/
} 
As nove edições...

\begin{tabular}{|c|c|c|c|}
\hline $\begin{array}{c}\text { VI } \\
2009\end{array}$ & $\begin{array}{l}\text { Juiz de Fora/MG } \\
\text { UFJF }\end{array}$ & $\begin{array}{c}\text { CARTOGRAFIA PARA CRIANÇAS E } \\
\text { ESCOLARES } \\
\text { // Fórum Latino Americano de Cartografia para } \\
\text { Escolares } \\
\text { Sítio do evento: } \\
\frac{\text { http://cartografiaescolar.blogspot.com.br/2009/0 }}{8 / \text { vi-coloquio-de-cartografia-para.html }}\end{array}$ & $\begin{array}{l}\text { Prof. Dr. Jader Janer M. Lopes e Prof. } \\
\text { Dr. }{ }^{a} \text { Valéria Trevizani Burla de Aguiar, } \\
\text { ambos da UFJF. }\end{array}$ \\
\hline $\begin{array}{l}\text { VII } \\
2011\end{array}$ & $\begin{array}{l}\text { Vitória/ES } \\
\text { UFES }\end{array}$ & $\begin{array}{c}\text { CARTOGRAF IA PARA CRIANÇAS E } \\
\text { ESCOLARES } \\
\text { Imaginação e inovação: desafios para a } \\
\text { Cartografia Escolar } \\
\text { Sítio do evento: } \\
\text { https://cartografiaescolar2011.wordpress.com/ }\end{array}$ & $\begin{array}{l}\text { Prof. Dr. André Luiz Nascentes Coelho } \\
\text { e Antônio Carlos Queiroz Filho, e } \\
\text { Prof. }^{\text {as }} \text { Dr. }^{\text {as }} \text { Gisele Girardi e Marisa } \\
\text { Terezinha Rosa Valladares, } \\
\text { vinculados à UFES. }\end{array}$ \\
\hline $\begin{array}{l}\text { VIII } \\
2013\end{array}$ & $\begin{array}{c}\text { São João del-Rei/MG } \\
\text { UFSJ }\end{array}$ & $\begin{array}{c}\text { CARTOGRAFIA PARA CRIANÇAS E } \\
\text { ESCOLARES } \\
\text { Para quem e para que a Cartografia Escolar: } \\
\text { experiências e campos de saberes } \\
\text { Sítio do evento: } \\
\text { http://www.ufsj.edu.br/coloquiodecartografia/org } \\
\text { anizacao.php }\end{array}$ & $\begin{array}{l}\text { Prof. }{ }^{\text {as }} \text { Dr. }^{\text {as }} \text { Lígia Maria Brochado de } \\
\text { Aguiar, Silvia Elena Ventorini, e Carla } \\
\text { Juscélia de Oliveira Souza, vinculadas } \\
\text { à UFSJ. }\end{array}$ \\
\hline $\begin{array}{c}\text { IX } \\
2016\end{array}$ & $\begin{array}{c}\text { Goiânia/GO } \\
\text { UFG (Campus I) e } \\
\text { PUC/GO }\end{array}$ & $\begin{array}{c}\text { CARTOGRAFIA PARA CRIANÇAS E } \\
\text { ESCOLARES } \\
\mathbf{2 0} \text { anos do Colóquio: percursos e } \\
\text { perspectivas da Cartografia para Crianças e } \\
\text { Escolares } \\
\text { Sítio do evento: } \\
\text { http://geceufg.wixsite.com/coloquiocartografia }\end{array}$ & 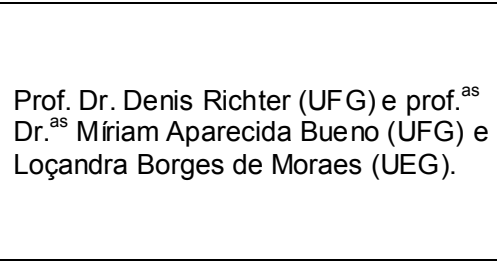 \\
\hline $\begin{array}{c}X \\
2018\end{array}$ & $\begin{array}{c}\text { São Paulo/SP } \\
\text { USP - Campus Butanta }\end{array}$ & $\begin{array}{c}\text { CARTOGRAFIA PARA CRIANÇAS E } \\
\text { ESCOLARES } \\
\text { As diferentes linguagens no mundo } \\
\text { contemporâneo } \\
\text { I Encontro Internacional de Cartografia Escolar e } \\
\text { Pensamento Espacial } \\
\text { Sítio do evento: } \\
\text { http://veradata.com.br/cartografiaescolar/?q=pt- } \\
\text { br }\end{array}$ & $\begin{array}{l}\text { Prof }{ }^{\text {as }} \text { Dr. }{ }^{\text {as }} \text { Andrea Coelho Lastória } \\
\text { (FFCLRP-USP); Carla Cristina de } \\
\text { Sena (UNESP/Ourinhos); Paula } \\
\text { Cristiane Strina Juliasz ( FE-USP); } \\
\text { Sônia Maria Vanzella Castellar( FE e } \\
\text { DG/USP); Waldirene Ribeiro do } \\
\text { Carmo (DG- USP); e prof. Dr. Ronaldo } \\
\text { Goulart Duarte (UERJ). }\end{array}$ \\
\hline
\end{tabular}

Elaboração: Valéria Cazetta, 2018.

A noção de cartografia infantil refere-se àquelas "atividades preparatórias" realizadas na educação infantil ${ }^{8}$ para que depois as crianças realizem "concretamente as operações mentais de redução, rotação e generalização, que são propriedades fundamentais do processo de mapeamento" (OLIVEIRA, 1978, p. 36). Ainda, segundo Oliveira (1978, p. 36) "para que o desenvolvimento de uma cartografia infantil seja eficaz, é preciso considerar o mapa como um entre os vários tipos de linguagem de que os homens dispõem para se comunicarem e se expressarem". O escopo dos estudos desse grupo de pesquisadoras tinha, na faixa etária abrangida pela educação infantil, o eixo empírico de suas práticas investigativas realizadas até então, com a finalidade de compreender como o espaço era concebido, representado e projetado pelas crianças no plano bidimensional do papel. Tais estudos assentavam-se no registro teórico piagetiano acerca da psicogênese das operações espaciais na criança. Essas pesquisas operaram como

\footnotetext{
${ }^{8}$ Refere-se, no Brasil, à educação pré-escolar, isto é, a etapa inicial da Educação Básica; e conforme a Lei de Diretrizes e Bases da Educação Nacional (LDBEN 9.394/96), que atende crianças na faixa etária entre zero a 5 anos. "Na primeira fase de desenvolvimento, dos zero aos três, as crianças são atendidas nas creches ou instituições equivalentes. A partir daí até completar seis anos, frequentam as pré-escolas" (Disponível em: < http://www.brasil.gov.br/educacao/2012/04/creche> . Acesso em: 25 jan. 2018).
}

Estudos Geográficos, Rio Claro, 16(1): 159-179, jan./jun. 2018 (ISSN 1678-698X) 
farol nos desdobramentos dos estudos posteriores, incorporando investigações realizadas em âmbito escolar, desde as séries iniciais do ensino fundamental aos três anos do ensino médio da Educação Básica, de modo que a partir do IV Colóquio o adjetivo escolar foi incorporado ao título do evento, ampliando o escopo das pautas do referido evento.

Outra polêmica evidenciada foram as noções de alfabetização cartográfica (SIMIELLI, 1996; ALMEIDA, 1999; MARTINELLI, 1999; PASSINI, 1999) versus Iniciação cartográfica. Almeida (1999) ao problematizar o emprego da primeira em detrimento da segunda, partindo de estudos sobre a aquisição da leitura e escrita, argumenta que "o ensino da leitura e escrita, geralmente chamado de alfabetização que significa 'ação de ensinar o código alfabético', não consiste apenas em levar o aprendiz a codificar a língua escrita" (ALMEIDA, 1999, p. 131). Segundo a autora,

\begin{abstract}
Nesse processo interagem fatores pedagógicos, psicomotores, lingüísticos e sociais cuja abrangência reveste o domínio da língua escrita de maior complexidade. Essa é uma das razões de encontrarmos, na literatura estrangeira específica da área, a expressão "leitura e escrita" com maior freqüência do que "alfabetização", que predomina em português [...]. A leitura e escrita, como linguagem, partem de um significado, cuja compreensão é essencial para que haja comunicação através do código escrito, a compreensão, por sua vez, envolve toda uma bagagem sócio-cultural que o leitor deve possuir. (ALMEIDA, 1999, p.131).
\end{abstract}

Assim, "se 'alfabetização' é um termo limitador para designar a aquisição da leitura e escrita, tanto mais com relação à aquisição da linguagem cartográfica" (ALMEIDA, 1999, p.132), de modo que os estudantes, ao se apropriarem da linguagem cartográfica, processo que "pode assemelhar-se àquele da aquisição da leitura e escrita" (ALMEIDA, 1999, p.133), não significa que aprender a ler mapas trata-se de decifrar códigos. Almeida advoga em prol de que o

ensino da cartografia na escola deveria partir de uma "iniciação cartográfica" [...] como introdução à educação cartográfica que se desenvolveria ao longo de todo ensino fundamental, como parte da educação geográfica, da qual a cartografia é uma das principais linguagens. (p. 133).

Almeida ainda lamentou o equívoco do texto dos "Parâmetros Curriculares Nacionais" (PCN) de geografia para o terceiro ciclo do ensino fundamental ao optar pela noção de alfabetização cartográfica:

a alfabetização cartográfica compreende uma série de aprendizagens necessárias para que os alunos possam continuar sua formação nos elementos da representação gráfica já iniciada nos dois primeiros ciclos para posteriormente trabalhar com a representação cartográfica. (ALMEIDA, 1999, p. 133).

A partir de fins da década de 1990, o substantivo "alfabetização" também foi deslizado para o ensino de ciências (alfabetização científica), para o vasto campo da educação visual (alfabetização visual), entre outras áreas (GURIDI; CAZETTA, 2014). 
As nove edições...

\section{OS TEMAS DOS COLÓQUIOS: ENTRE O QUE DEVE E O QUE PODE A CARTOGRAFIA}

Além das duas polêmicas suprarreferidas, voltemo-nos para os temas das dez edições do Colóquio, já apresentados na tabela 1. Na quinta edição desse evento, um dos Grupos de Trabalho e de Diálogo (GTD), intitulado "Outras linguagens no ensino de geografia", adensou as comunicações orais sob essa envergadura. Após a finalização dos trabalhos, um documento ${ }^{9}$ foi elaborado pelo GTD e divulgado entre os seus participantes, no qual perspectivou-se a educação visual contemporânea e seus desdobramentos teóricos e metodológicos compostos tanto pela educação geográfica como pela cartografia escolar. Dois direcionamentos foram apontados a partir das comunicações orais apresentadas: um grupo que entende a educação geográfica como transmissão, no sentido de comunicar conhecimentos geográficos para os escolares/estudantes; e outro grupo cujos trabalhos ancoram-se nas diversas linguagens espraiadas pelo tecido social, na forja de conhecimentos geográficos via essas mesmas linguagens, tais como: histórias em quadrinhos (HQs), fotografias (em P\&B e coloridas) de diversos ângulos e escalas etc. Os direcionamentos mencionados foram decorrentes, no entendimento do GTD, dos modos como a noção de linguagem foi apropriada por ambos os grupos.

\footnotetext{
${ }^{9}$ Documento elaborado pelo Grupo de Trabalho e de Diálogo (GTD), "Outras linguagens no ensino de geografia", quando da realização do $1^{\circ}$ Simpósio Ibero-Americano de Cartografia para Criança. 2007, p. 1-3, Niterói (RJ).
} 
Desta forma, as linguagens não aparecem nestes trabalhos com o [único] sentido de comunicação, mas sobretudo com o sentido de criação, de produtoras da realidade ou de realidades, sendo que esta(s) realidade(s) pode $(\mathrm{m})$ ser tomada(s) como teórica(s), positiva(s) ou narrativa(s). Dependendo de como esta produção do real ou da realidade é tomada, os conceitos e categorias de análise/interpretação se dão em torno da representação, apresentação, diálogo, e/ou discurso.

A preocupação, portanto, deste segundo grupo de trabalhos é mais com a produção do conhecimento geográfico nas muitas linguagens nas quais ele nos chega [seja nas escolas ou fora delas] notadamente nas linguagens que se estruturam com e como imagens.

A ação do professor para este grupo é colocar em discussão estes universos culturais de produção de obras, de sentidos, de subjetividades, de geografias. Caberia ao professor de geografia, portanto, colocar em discussão consigo mesmo e com seus alunos a própria natureza [lingüística?] do conhecimento geográfico. ${ }^{10}$

Na sétima edição do evento, ocorrida em Vitória (ES) e intitulada "Imaginação e inovação: desafios para a Cartografia Escolar", a programação foi pautada da seguinte maneira:

Modificações promovidas pelas políticas educacionais e científicas, particularmente no último decênio, contribuíram com a consolidação do campo de pesquisa em Cartografia Escolar. Sua legitimação se expressa nas produções científicas, nos eventos, na produção de recursos didáticos, na disseminação por meio de atividades de formação continuada de professores e em sua inclusão no ensino universitário, seja como conteúdo das metodologias e práticas de ensino, seja como disciplina independente.

Tendo como horizonte o crescimento e fortalecimento deste campo de pesquisa, esse evento se propõe a ser um momento de reflexão acerca dos avanços nas diferentes linhas de pesquisa em Cartografia Escolar e de proposições estratégicas para a pesquisa nos próximos anos. Propõe-se, também, a se constituir em um momento de intercâmbio entre outros pesquisadores e grupos de pesquisa que articulam em sua produção os universos cartografiaeducação, sem, contudo, inserirem-se no âmbito das práticas escolares em Geografia, dando visibilidade à riqueza e potencialidade destes fazeres na contemporaneidade e, com isso, provocando a criação.

Constitui-se, assim, a temática proposta para este VII Colóquio de Cartografia para Crianças e Escolares, pilares a partir dos quais se buscará contribuir com avanços na pesquisa nesta área: Imaginação, como faculdade humana criadora, e Inovação, como horizonte necessário às novas proposições. ${ }^{11}$

Um dos eixos do evento, "Imaginações em cartografia: potências educativas", adensou os trabalhos atravessados por essa temática, evidenciando que os/as

\footnotetext{
${ }^{10}$ Idem.

${ }^{11}$ Excerto do site do evento: https://cartografiaescolar2011.wordpress.com/ Acesso em: 19/11/2017.
} 
autores e autoras passaram a compor seus estudos com outros referenciais teóricos e metodológicos para além do registro piagetiano, e de Jacques Bertin (Semiologia Gráfica). Nota-se, na temática dessa edição do evento, um ponto de inflexão, também seguido na oitava edição, conforme excerto a seguir:

O tema escolhido, "Para quem e para que a Cartografia Escolar: experiências e campos de saberes", tem como objetivo engajar os potenciais educativos da imaginação geográfica em outra artesania: aquela que através de interlocuções inevitáveis, de atrevimentos investigativos e interpretativos, sobretudo, de experiências que incorporem a diversidade de tempos e espaços, atualize os processos singulares da atividade cognitiva criadora, o que por si só configura outros devires pedagógicos, outras territorialidades no campo da Cartografia Escolar. ${ }^{12}$

Aqueles que estiveram na edição do colóquio de Vitória presenciaram um embate acalorado, tributário da mesa-redonda "Cartografias Intensivas"13, na qual Ana Maria Hoepers Preve apresentou os resultados de sua tese de doutorado, intitulada Mapas, prisão e fugas: cartografias intensivas em educação ${ }^{14}$ (PREVE, 2010), que versa sobre a realização de oficinas, envolvendo o tema Geografia e Meio Ambiente, junto aos internos do Hospital de Custódia e Tratamento Psiquiátrico de Florianópolis/SC.

O foco inicial das oficinas era investigar o pensamento geográfico e as articulações espaciais dos detentos com suas vidas restritas ao espaço prisional. $O$ estudo e a produção de mapas, pelos participantes, contou com a emergência de várias outras produções gráficas dos mesmos. Tomadas, num primeiro momento, como ruído, essas produções (desenhos, relatos, fotos), de tão recorrentes, passaram a ser consideradas e tornaram-se o foco mesmo das investigações, na medida em que problematizavam, entre outras coisas, o aprisionamento e a co-extensiva medicalização a que estavam sujeitos, gerando a noção-ferramenta de mapas intensivos [...] As oficinas colocam-se, portanto, como estratégia educacional interessada na cartografia das contingências e dos processos em que surgem os mapas intensivos. E é com isso que adquire consistência a noção de geografias intensivas. (PREVE, 2010, p. ix).

O objetivo de Preve foi realizar um trabalho de composição entre as possibilidades de abordagem teórica e metodológica apontadas, até então, pelo grupo de cartografia escolar brasileiro, sincronizada aos próprios limites da referida abordagem. Assim, cada uma das produções dos oficineiros foi

tomada como um mapa intensivo. Mapas de uma ordem distinta dos produzidos pela Cartografia Científica, cujo foco concentra-se na superfície extensiva da Terra. Os mapas intensivos não podem ser descolados dos processos em que surgiram. Esses processos, em

\footnotetext{
${ }^{12}$ Excerto do site do evento: https://ufsj.edu.br/coloquiodecartografia/ Acesso em 22/11/2017.

${ }^{13}$ Programação disponível em: https://cartografiaescolar2011.files.wordpress.com/2012/03/vii-ccce-programacao.pdf. Acesso em: 10 jan. 2018.

${ }^{14}$ Disponível em: http://repositorio.unicamp.br/handle/REPOSIP/251335. Acesso em: 12 ago. 2017.
} 
bloco, é o que chamo aqui de cartografias intensivas. E os mapas intensivos não são tomados como resultado de procedimentos cartográficos - como técnica de produção de mapas da cartografia científica -, mas como movimento no processo. São mapas na medida em que permitem apresentar o processo, mas deixam de sêlo se se quiser utilizá-los como guia, orientador, indicador ou localizador; eles não levam a lugar nenhum, não servem para identificar quem os desenhou, tampouco para subsidiar diagnósticos de qualquer ordem, e, nesse sentido, eles querem, antes, confundir. (PREVE, 2010, p. 18).

O debate profícuo ocorrido no decorrer do VII Colóquio foi fagocitado por certo endereçamento de alguns grupos ali presentes, no sentido de pautar o que deve ser a cartografia escolar brasileira, perdendo, talvez, a chance de abrir o debate acerca daquilo que pode a cartografia tanto do ponto de vista da educação geográfica como das pedagogias culturais (ANDRADE; COSTA, 2015a, 2015b, 2017; WORTMANN; COSTA, 2015), dado o espraiamento das linguagens cartográficas e do Sensoriamento Remoto, supostamente localizados nas ciências geográfica e cartográfica, no tecido social.

Finalmente, o tema da nona edição comemorativa aos 20 anos do Colóquio, Percursos e Perspectivas da Cartografia para Crianças e Escolares, bem como de sua décima edição, As diferentes linguagens no mundo contemporâneo, propuseram-se, respectivamente

a resgatar os percursos trilhados ao longo do desenvolvimento desta linha de pesquisa no Brasil, neste caso iniciado em 1978 - com a publicação da tese de livre docência da profa. Lívia de Oliveira - e, ao mesmo tempo, reconhecer as novas perspectivas que indicam os caminhos que a Cartografia Escolar deverá percorrer nos próximos anos, identificando os desafios e as demandas que ainda se fazem presentes na sua relação com o ensino e em outros espaços ${ }^{15}[\ldots]$.

resgatar os percursos trilhados, ao longo do desenvolvimento dessa linha de pesquisa, em diferentes programas de pós-graduação de mestrado e doutorado nas universidades brasileiras. Isso sem ignorar o reconhecimento das novas perspectivas que indicam os caminhos da Cartografia Escolar a serem percorridos nos próximos anos, considerando as demandas referentes ao processo de ensino e de aprendizagem na educação básica ${ }^{16}$.

Interessante o verbo empregado para descrever a finalidade dessas duas últimas edições do colóquio: resgatar. Seria uma tentativa de retomar, quiçá, certa identidade à cartografia escolar brasileira? Por que os discursos dos estudiosos e pesquisadores da cartografia escolar ainda continuam sendo pautados pela "síndrome do resgate"?

A "síndrome do resgate" mobiliza atividades mitificadoras, pois ela opera transformando o que já é um significado em um pretenso

\footnotetext{
${ }^{15}$ Excerto do site do evento: http://docs.wixstatic.com/ugd/10c2d1_1f69ae18372c48718a0f2a2c781be97a.pdf Acesso em: $22 / 11 / 2017$.

${ }^{16}$ Excerto do site do evento, disponível em: http://veradata.com.br/cartografiaescolar/?q=pt-br/sobre Acesso em: 26 jan. 2018.
} 
significante. Ela fabrica o passado dizendo tê-lo encontrado, constróise a janela dizendo que ela já estava aí. Faz do ato de ver uma ação unidirecional, partindo do observador para o observado sem que esse interfira em como é visto. Faz de conta que o objeto não emerge na relação com esse olhar, já estando pronto, dado como uma evidência para ser apanhado pelo olhar que the permanece exterior. Não sendo fruto, isso sim, de dada vidência, uma dada maneira de ver, que interpela a empiricidade e que conforme ela o refrata, nessa relação agônica e diferencial surgirá como objeto. (ALBUQUERQUE JÚNIOR, 2013, p. 227).

A temática da décima edição ${ }^{17}$ retoma, de certo modo, aquela do GTD do $\mathrm{V}$ Colóquio (2007), Outras linguagens no ensino de geografia, bem como a de sua sétima edição (2011), Imaginação e inovação: desafios para a Cartografia Escolar, ao realizar simultaneamente o I Encontro Internacional de Cartografia Escolar e Pensamento Espacial. A justificativa do tema para o I Encontro foi atender as "demandas referentes ao processo de ensino e de aprendizagem na educação básica"18, e

uma dessas novas e promissoras perspectivas é o campo de pesquisas que vem sendo denominado como Pensamento Espacial, seara interdisciplinar de grande potencial teórico-metodológico e cuja produção acadêmica vem crescendo aceleradamente em diversos países. ${ }^{19}$

No que diz respeito aos trabalhos publicados nos anais das seis edições do evento Almeida e Almeida (2014) agrupou-os em quatro temáticas:

- Representação do espaço, que inclui conteúdos de cunho teórico a respeito da representação espacial pela criança, linguagem cartográfica, mapas mentais e representação de conceitos sócio-espaciais;

- Metodologia de ensino, que envolve conteúdos teórico-práticos voltados para a busca de caminhos didáticos no ensino da cartografia escolar, incluindo iniciação cartográfica (alfabetização cartográfica), educação especial (deficiência visual) e ensino-aprendizagem de habilidades e conceitos específicos da cartografia nos três níveis da Educação Básica;

- Tecnologias e produção de materiais didáticos cartográficos, incluindo trabalhos a respeito de atlas escolares, maquetes, cartografia multimídia, mapas e internet, educação à distância, sensoriamento remoto e geoprocessamento;

- Formação de professores e currículo, incluindo pesquisas sobre saberes e práticas docentes, cotidiano escolar, cultura, currículo e formação de professores. (ALMEIDA e ALMEIDA, 2014, p. 889)

Afirmamos, de modo geral, que tal agrupamento manteve-se nos trabalhos publicados nos anais das três últimas edições. Na tabela 2, demos continuidade

\footnotetext{
${ }^{17}$ Excerto do site do evento, disponível em: http://veradata.com.br/cartografiaescolar/?q=pt-br Acesso em: 26 jan. 2018.

${ }^{18}$ Excerto do site do evento, disponível em: http://veradata.com.br/cartografiaescolar/?q=pt-br/sobre Acesso em: 26 jan. 2018.

${ }^{19}$ Idem.
} 
àquela elaborada por Almeida e Almeida (2014) e confeccionamos a tabela 3 para a quinta edição do colóquio - evento sobreposto à realização da nona edição do Encontro Nacional de Prática de Ensino em Geografia (ENPEG), ocorrido em Niterói (RJ) -, organizado por eixos não habituais em relação aos colóquios anteriores e posteriores a ele: "representações gráficas e experiências internacionais e interculturais".

Tabela 2: Trabalhos publicados nos anais das nove edições do Colóquio de Cartografia para Crianças e Escolares (em números absolutos)

\begin{tabular}{|l|c|c|c|c|c|c|c|c|}
\hline & \multicolumn{7}{|c|}{ EDIÇÕES DO COLÓQUIO } \\
\hline \multicolumn{1}{|c|}{ TEMA } & I & II & III & IV & VI & VII & VIII & IX \\
\hline $\begin{array}{l}\text { Representação do } \\
\text { espaço }\end{array}$ & 4 & 4 & 6 & 22 & 6 & 5 & 48 & 39 \\
\hline $\begin{array}{l}\text { Metodologia de } \\
\text { ensino }\end{array}$ & 11 & 16 & 2 & 16 & 19 & 18 & 7 & 5 \\
\hline $\begin{array}{l}\text { Tecnologias e } \\
\text { materiais didáticos }\end{array}$ & 1 & 8 & 14 & 37 & 13 & 12 & 24 & 21 \\
\hline $\begin{array}{l}\text { Cartografia e } \\
\text { Educação não- } \\
\text { formal }\end{array}$ & & & & & & 1 & 0 & 4 \\
\hline $\begin{array}{l}\text { Formação de } \\
\text { professores e } \\
\text { currículo }\end{array}$ & 1 & 2 & 0 & 2 & 8 & 4 & 13 & 19 \\
\hline Total & $\mathbf{1 7}$ & $\mathbf{3 0}$ & $\mathbf{2 2}$ & $\mathbf{7 7}$ & $\mathbf{4 6}$ & $\mathbf{3 9}$ & $\mathbf{9 2}$ & $\mathbf{8 8}$ \\
\hline
\end{tabular}

Obs. 1: Para o V Colóquio elaboramos uma tabela à parte, pois tratou-se de evento sobreposto ao $9^{\circ}$ ENPEG.

Obs. 2: Tabela elaborada a partir de Almeida e Almeida (2014, p. 890).

Tabela 3: V Colóquio/l Simpósio Ibero-Americano de Cartografia para Criança

\begin{tabular}{|l|c|}
\hline \multicolumn{1}{|c|}{ TEMA } & Trabalhos publicados \\
\hline Representações gráficas & 23 \\
\hline Representações cartográficas & 23 \\
\hline Novas tecnologias & 14 \\
\hline $\begin{array}{l}\text { Experiências Internacionais e } \\
\text { interculturais }\end{array}$ & 5 \\
\hline $\begin{array}{l}\text { Atlas - concepção e } \\
\text { metodologia }\end{array}$ & 14 \\
\hline Total & 79 \\
\hline
\end{tabular}

Elaboração: Cazetta, 2018. 
As nove edições...

\section{CONSIDERAÇÕES FINAIS}

Concluiremos esse texto advogando em prol de uma educação geográficocartográfica pelo arquivo, o que "não implica nenhum apelo ao enciclopedismo ou à restauração memorialística, tal como, em alguma medida, reclamam as pedagogias conservacionistas", mas ao contrário, "é do murmúrio descontínuo da história, e não da preservação de uma tradição estanque que se trata, tanto menos de uma obediência muda aos cânones do conhecimento acumulado" (AQUINO, 2017, p. 687-688).

Em sua palestra no $V$ Colóquio Internacional $A$ educação pelas Imagens e suas Geografias, Gisele Girardi abordou o pensamento espacial apresentando o que seria pensar o espaço e nele se deslocar desde uma perspectiva continental, ou desde uma perspectiva ilhéu. Vale a leitura do excerto:

Nos mapas de deslocamentos continentais linhas variadas em cores, espessuras e formas nos dão os caminhos fixos no terreno pelos quais nos deslocamos para chegar a algum lugar. Para o deslocamento oceânico há também rotas, conjunto de posicionamentos a ser tomados pelas embarcações, e portos, o nó que conecta os deslocamentos em água aos deslocamentos em terra. Mas o que os mapas pouco enfatizam é que o movimento das massas oceânicas, suas ondulações, produzem um meio completamente diferente para o deslocamento. (GIRARDI, 2017) ${ }^{20}$

Girardi problematizará, no decorrer de sua exposição, o quê e como seria um mapa do mar elaborado a partir do pensamento ilhéu, abordando desde um gesto arquivístico os Armij Aelon Kein - habitantes de Aelon Kein Ad, arquipélago localizado no Oceano Pacífico, composto por vinte nove atóis e cinco ilhas -, que compunham com a natureza, com os barcos, com os mapas elaborados e com seus corpos um modo de vida instaurador de existência. "Para que um ser, coisa, pessoa ou obra conquiste existência - e não apenas exista -, é preciso que ele seja instaurado" (PELBART, 2016, p.393).

Deyse Cristina Brito Fabricio $(2017)^{21}$ estudou, por sua vez, a temática cartográfica medieval, selecionando os seguintes documentos:

a) três mapas-múndi medievais T-O dos séculos XII e XIII: o do arcebispo Isidoro de Sevilha, o de Psalter (confeccionado aproximadamente na década de 1260), e o de Ebstorf (ano de 1236);

b) mapas dos livros de fantasia épica de John Ronald Reuel Tolkien (2002, 2003) e de Clive Staple Lewis (2009), afinal, a temática do medievo é frequente na fantasia épica; e

c) quatro vídeos em time-lapse, sendo que os três primeiros são oriundos de Peter Draws, canal do desenhista e ilustrador Peter Deligdisch. No primeiro vídeo, Fantasy Map Drawing ${ }^{22}$, Deligdisch cartografa o reino fictício de Amura; no segundo vídeo, Worldbuilding: Elzur (Les Ecuyers de l'Espoir) ${ }^{23}$, o

\footnotetext{
${ }^{20}$ Anotações da palestra "Cartografias (im)possíveis II", ministrada pela profa. Gisele Girardi, no V Colóquio Internacional a Educação pelas Imagens e suas geografias / XVII Simpósio de Geografia da UDESC, em Florianópolis (SC), em 8 de novembro de 2017. Programação do evento disponível em: https://5coloquioimagensblog.wordpress.com/programacao/

${ }^{21}$ Esse estudo resultou na dissertação de mestrado de Fabrício (2017), sob orientação da profa. dra. Valéria Cazetta (USP), defendida no Programa de Pós-Graduação em Ensino e História de Ciências da Terra, Instituto de Geociêncas da Unicamp, e disponível em: http://repositorio.unicamp.br/bitstream/REPOSIP/322238/1/Fabricio DeyseCristinaBrito M.pdf

${ }^{22}$ Disponível em: https:/www.youtube.com/watch?v=-6V902YqU94 Acesso em: 08 Fev. 2018.

${ }^{23}$ Disponível em: https://www.youtube.com/watch?v=ZKk2NdsisNU Acesso em: 08 Fev. 2018.
} 
desenhista cria o Reino de Elzur, baseado na literatura francesa; e no terceiro vídeo, Deligdisch cria o Reino de Arcádia: Worldbuilding: Arcádia (Part 2) ReUpload $^{24}$. Por fim, no quarto vídeo, The making of a map of Middle Earth ${ }^{25}$, a Terra Média e os lugares imaginados por Tolkien são apresentados por meio da técnica da pirografia pelo artista Kfir Mendel.

O conjunto de práticas educativas desenvolvidas junto de estudantes do ensino médio foi delineado após um percurso de trabalho em acervos analógicos e digitais (disponibilizados online), coletando desde mapas medievais aos vídeos do website americano youtube, suprarreferidos. A finalidade do estudo de Fabrício foi desnaturalizar, junto aos estudantes do ensino médio da educação básica, os mapas hegemônicos - aqueles produzidos pelas instituições de pesquisa ligadas ou não ao estado brasileiro -, porque, na maioria das vezes, são esses os únicos documentos cartográficos que compõem a imaginação espacial dos estudantes. Os mapas das publicações de fantasia épica "não fazem parte da cartografia 'oficial', pois os materiais didáticos de Geografia privilegiam os 'mapas ocidentais"' (FABRÍCIO, 2017, p. 12).

Os estudos de Girardi e Fabrício apresentados, ainda que de forma lacônica, permite-nos vislumbrar a força de uma educação geográfica e cartográfica pautada pelo gesto arquivístico, o qual pode possibilitar a instauração de "conexões vigorosas entre os mortos das obras e os vivos das aulas" (AQUINO, 2017, p.686).

\section{REFERÊNCIAS}

ALBUQUERQUE JÚNIOR, Durval Muniz. A feira dos mitos: a fabricação do folclore e da cultura popular (nordeste - 1920-1950). São Paulo, SP: Intermeios, 2013.

ALMEIDA, Rosângela Doin de. Podemos estabelecer paralelos entre o ensino de leitura e escrita e o ensino de mapas? In: Boletim de Geografia, Maringá, PR, v. 17, n. 01, 1999, p. 131-133. Disponível em:

http://periodicos.uem.br/ojs/index.php/BolGeogr/article/view/12069/7312 Acesso em: 25 jan. 2018.

ALMEIDA, Rosângela Doin de (Org.). Cartografia Escolar. São Paulo, SP: Contexto, 2010.

ALMEIDA, Rosângela Doin de; ALMEIDA, Regina Araújo de. Fundamentos e perspectivas da cartografia escolar no Brasil. Revista Brasileira de Cartografia, v. 66, n. 4, jul./ago. 2014. p. 885-897. Disponível em:

http://www.lsie.unb.br/rbc/index.php/rbc/article/view/929/717 Acesso em: 10 de jan. de 2018.

ANDRADE, Paula Deporte; COSTA, Marisa Vorraber. Usos e possibilidades do conceito de pedagogias culturais nas pesquisas em estudos culturais em educação. Textura, Canoas, RS, v. 17, n. 34, p. 48-63, mai./ago. 2015a. Disponível em:

http://www.periodicos.ulbra.br/index.php/txra/article/viewFile/1501/1140. Acesso em: 17 jan. 2018.

\footnotetext{
${ }^{24}$ Disponível em: https://www.youtube.com/watch?v=KzRL4xPeEGw Acesso em: 08 Fev. 2018.

${ }^{25}$ Disponível em: https://www.youtube.com/watch?v=VXs5Fya0Mto Acesso em: 08 fev. 2018.
} 
ANDRADE, Paula Deporte; COSTA, Marisa Vorraber. Na produtiva confluência entre educação e comunicação, as pedagogias culturais contemporâneas. Perspectiva, Florianópolis, SC, v. 33, n. 2, p. 843 - 862, mai./ago. 2015b. Disponível em:

http://www.perspectiva.ufsc.br. Acesso em: 18 jan.2018.

ANDRADE, Paula Deporte; COSTA, Marisa Vorraber. Nos rastros do conceito de pedagogias culturais: invenção, disseminação e usos. Educação em Revista, Belo Horizonte, MG, n. 33, 2017. Disponível em: http://dx.doi.org/10.1590/01024698157950. Acesso em: 18 jan. 2018.

AQUINO, Julio Groppa. Defender a escola das pedagogias contemporâneas. Educação Temática Digital, Campinas, SP, v. 19, n. 4, p. 669690, out. 2017. Disponível em:

<https://periodicos.sbu.unicamp.br/ojs/index.php/etd/article/view/8648729>. Acesso em: 12 fev. 2018.

BANYAI, Istvan. Zoom. Tradução de Gilda de Aquino. Rio de Janeiro, RJ: Brinque Book, 1995.

Re-Zoom. USA: Puffin Books, 1998.

BENJAMIN, Walter. Rua de mão única. São Paulo, SP: Brasiliense, 2000. (Obras escolhidas, v. II).

BORGES, Jorge Luís. Sobre o rigor na ciência. In: infâmia. Tradução de José Bento. Lisboa: Assírio \& Alvim, 1982.

DELEUZE, Gilles; GUATTARI, Félix. Micropolítica e segmentaridade. In: Mil Platôs. Capitalismo e Esquizofrenia 2. $2^{\mathrm{a}}$ Ed. Tradução de GUERRA NETO, Aurélio; OLIVEIRA, Ana Lúcia de; LEÃO, Lúcia Cláudia; ROLNIK, Suley. São Paulo, SP: Editora 34, 2012. p. 91-126.

DIDI-HUBERMAN, Georges. Quando as imagens tomam posição. Tradução de Cleonice Paes Barreto Mourão. Belo Horizonte, MG: Editora UFMG, 2017. (O olho da História, I)

. Cascas. Tradução de André Telles. São Paulo, SP: Editora 34, 2017.

ECO, Umberto. O segundo diário mínimo. Tradução de Sérgio Flaksman. Rio de Janeiro, RJ: Record, 1993.

FABRÍCIO, Deyse Cristina Brito. Mapas medievais e de fantasia épica na geografia escolar do ensino médio: questionamentos das práticas do cartografar. Mestrado. Universidade Estadual de Campinas. Campinas (SP): Unicamp, 2017.

GIRARDI, Gisele. Funções de mapas e espacialidade: elementos para modificaçãoo da cultura cartográfica na formação em Geografia. Revista Brasileira de

Cartografia, v. 66, n. 4, jul./ago. 2014. p. 861-876. Disponível em: http://www.Isie.unb.br/rbc/index.php/rbc/article/view/927/715 Acesso em: 10 de jan. de 2018.

GURIDI, Verônica Marcela e CAZETTA, Valéria. Alfabetização científica e cartográfica no ensino de ciências e geografia: polissemia do termo, processos de enculturação e suas implicações para o ensino. Revista de Estudos Culturais, São Paulo, SP, n. 1, 2014, p. 1-16. Disponível em: 
https://www.revistas.usp.br/revistaec/article/view/98376/97111 Acesso em: 25 jan. 2018.

LEWIS, Clive Staple. As crônicas de Nárnia. Ilustração de Pauline Baynes. São Paulo, SP: Martins Fontes, 2009.

MARTINELLI, Marcello. Alfabetização Cartográfica. In: Boletim de Geografia, Maringá, v. 17, n. 01, 1999, p. 134-135. Disponível em:

http://periodicos.uem.br/ojs/index.php/BolGeogr/article/view/12069/7312 Acesso em: 25 jan. 2018.

OLIVEIRA, Lívia de. Estudo metodológico e cognitivo do mapa. 1978. 128 f. Tese (Livre Docência) - Departamento de Geografia e Planejamento do Instituto de Geociências e Ciências Exatas da Universidade Estadual Paulista, Rio Claro, 1978.

PASSINI, Elza Yasuko. O que significa alfabetização científica? In: Boletim de Geografia, Maringá, v. 17, n. 01, 1999, p. 125-130. Disponível em: http://periodicos.uem.br/ojs/index.php/BolGeogr/article/view/12069/7312 Acesso em: 25 jan. 2018.

PELBART, Peter Pál. Por uma arte de instaurar modos de existência. In: 0 avesso do niilismo. Cartografias do esgotamento. $2^{\mathrm{a}}$ Ed., São Paulo, SP: n-1 edições, 2016. p.391-419.

PRADO, Adélia. Terra de Santa Cruz. Rio de Janeiro, RJ: Record, 2006.

PREVE, Ana Maria H. Mapas, Prisões e Fugas: cartografias intensivas em educação. 2010. 267f. Tese (Doutorado em Educação) - Universidade Estadual de Campinas, Campinas, 2010.

SANTOS, Boaventura de Sousa. A crítica da razão indolente: contra o desperdício da experiências. São Paulo, SP: Cortez, 2000.

SIMIELLI, Maria Elena Ramos. Cartografia e ensino, proposta e contraponto de uma obra didática. Tese (Livre Docência), São Paulo, FFLCH - Universidade de São Paulo, 1996.

TOLKIEN, John Ronald Reuel. O Hobbit. São Paulo, SP: Martins Fontes, 2003.

. O Senhor dos Anéis. São Paulo, SP: Martins Fontes, 2002.

WORTMANN, Maria Lúcia Castagna; COSTA, Marisa Vorraber; SILVEIRA, Rosa Maria Hessel. Sobre a emergência e a expansão dos Estudos Culturais em educação no Brasil. Educação, Porto Alegre, RS, v. 38, n. 1, p. 32-48, jan./abr. 2015. Disponível em: http://dx.doi.org/10.15448/1981-2582.2015.1.18441 Acesso em: 18 jan. 2018.

REFERÊNCIAS (nove edições do Colóquio de Cartografia para Crianças e Escolares)

ALMEIDA, Rosângela Doin; VASCONCELLOS, Regina (Org.) COLÓQUIO CARTOGRAFIA PARA CRIANÇAS, 1., 1995, Rio Claro (SP). Anais... Rio Claro (SP): LABENGEO (Departamento de Educação, UNESP)/LEMADI (Departamento de Geografia, FFLCH, USP), 1995.

LE SANN, Janine Gisèle. (Org.). COLÓQUIO CARTOGRAFIA PARA CRIANÇAS, 2., 
1996, Belo Horizonte (MG). Anais. Revista Geografia e Ensino, Belo Horizonte, v. 6, n. 1, 1996.

SANTOS, Clézio. (Org.). COLÓQUIO CARTOGRAFIA PARA CRIANÇAS, 3., 1999, São Paulo (SP). Anais... São Paulo (SP): AGB - Seção Local São Paulo, 1999.

PASSINI, Elza Yasuko. (Org.). COLÓQUIO CARTOGRAFIA PARA CRIANÇAS, 4., Maringá (PR), 2001. Anais. Boletim de Geografia, UEM, Maringá (PR), v. 19, n. 2, 2001. Disponível em: <

http://www.periodicos.uem.br/ojs/index.php/BolGeogr/issue/view/569/showToc>. Acesso em: 10 out. 2017.

LOPES, Jader Janer Moreira; PAGANELLI, Tomoko lyda. (Org.). COLÓQUIO CARTOGRAFIA PARA CRIANÇAS E ESCOLARES, 5., SIMPÓSIO IBERO AMERICANO DE CARTOGRAFIA PARA CRIANAS, 1., ENCONTRO NACIONAL DE PRÁTICA DE ENSINO DE GEOGRAFIA, 9., 2007, Niterói (RJ). Anais... Juiz de Fora (MG): FEME, 2007. 1 CD-ROM.

AGUIAR, Valéria Trevizani Burla de. (Org.). COLÓQUIO CARTOGRAFIA PARA CRIANÇAS E ESCOLARES, 6., II FORUM LATINOAMERICANO DE CARTOGRAFIA PARA ESCOLARES, 2009, Juiz de Fora (MG). Anais... Juiz de Fora (MG): UFJF, 2009. 1 CD-ROM.

GIRARDI, Gisele. (Org.). COLÓQUIO CARTOGRAFIA PARA CRIANÇAS E ESCOLARES, 7., 2011, Vitória (ES). Anais eletrônicos... Vitória (ES): UFES, 2011. Disponível em: < https://cartografiaescolar2011.wordpress.com/anais-trabalhosapresentados-em-comunicacoes-orais-e-posteres/>. Acesso em: 09 set. 2017.

AGUIAR, Lígia Maria Brochado de; VENTORINI, Silvia Elena; SOUZA, Carla Juscélia de Oliveira. (Org.). COLÓQUIO CARTOGRAFIA PARA CRIANÇAS E ESCOLARES, 8., 2013, São João del-Rey (MG). Anais... São João del Rey (MG): UFSJ, 2013. 1 CD-ROM.

RICHTER, Denis; BUENO, Míriam Aparecida; MORAES, Loçandra Borges de. Org.). COLÓQUIO CARTOGRAFIA PARA CRIANÇAS E ESCOLARES, 9., 2016, Goiânia (GO). Anais eletrônicos... Goiânia (GO): UFG, 2016. Disponível em: <http://docs.wixstatic.com/ugd/10c2d1 19939615b2164018bc38913fbf5ef41c.pdf>. Acesso em: 10 nov. 2017. 